\title{
High-cell-density fed-batch cultivations of Vibrio natriegens
}

\author{
Isabel Thiele • Björn Gutschmann • Linus Aulich • Marcel Girard • \\ Peter Neubauer $\cdot$ Sebastian L. Riedel $(1)$
}

Received: 26 February 2021 / Accepted: 10 May 2021 / Published online: 19 May 2021

(C) The Author(s) 2021

\begin{abstract}
Objectives With generation times of less than 10 min under optimal conditions, the halophilic Vibrio natriegens is the fastest growing non-pathogenic bacterium isolated so far. The availability of the full genome and genetic engineering tools and its ability to utilize a wide range of carbon sources make $V$. natriegens an attractive host for biotechnological production processes. However, high-celldensity cultivations, which are desired at industrialscale have not been described so far.

Results In this study we report fed-batch cultivations of $V$. natriegens in deep-well plates and lab-scale bioreactor cultivations at different temperatures in mineral salt medium (MSM). Upon switching from exponential glucose to constant glucose-feeding cell death was induced. Initial $\mathrm{NaCl}$ concentrations of $15-18 \mathrm{~g} \mathrm{~L}^{-1}$ and a temperature reduction from 37 to $30{ }^{\circ} \mathrm{C}$ had a positive effect on cell growth. The maximal growth rate in MSM with glucose was 1.36
\end{abstract}

Supplementary Information The online version of this article (doi:https://doi.org/10.1007/s10529-021-03147-5) contains supplementary material, which is available to authorized users.

I. Thiele · B. Gutschmann · L. Aulich .

M. Girard · P. Neubauer · S. L. Riedel $(\bowtie)$

Chair of Bioprocess Engineering, Institute of

Biotechnology, Technische Universität Berlin, Berlin,

Germany

e-mail: riedel@tu-berlin.de $\mathrm{h}^{-1}$ with a specific oxygen uptake rate of $22 \mathrm{mmol}$ $\mathrm{g}_{\mathrm{CDW}}{ }^{-1} \mathrm{~h}^{-1}$. High biomass yields of up to $55 \mathrm{~g} \mathrm{~L}^{-1}$ after only $12 \mathrm{~h}$ were reached.

Conclusions The shown fed-batch strategies demonstrate the potential of $V$. natriegens as a strong producer in industrial biotechnology.

Keywords High-cell-density cultivations .

Fed-batch · Vibrio natriegens · Fast growing microorganism $\cdot$ Parallel bioreactor cultivations . Deep-well plate

\section{Introduction}

Only recently the potential of Vibrio natriegens (formerly known as Pseudomonas natriegens and Beneckea natriegens) has been rediscovered for biotechnological applications. The halophilic Gramnegative $\gamma$-proteobacterium was first isolated from salt marsh mud in 1961 (Eagon 1961) and is still the fastest-growing non-pathogenic bacterium reported so far (Long et al. 2017). Vibrio natriegens requires $\mathrm{Na}^{+}$, $\mathrm{Mg}^{2+}$ and $\mathrm{K}^{+}$for the induction of enzymes involved in substrate uptake and utilization for its outstandingly fast growth (Eagon 1961; Rhodes and Payne 1962). Similar to the model organism Escherichia coli, it is facultatively anaerobic, prefers neutral $\mathrm{pH}$, has an optimal growth temperature of $37{ }^{\circ} \mathrm{C}$ and shows a 
similar core metabolism under aerobic growth on glucose (Long et al. 2017). However, in complex media $V$. natriegens has a generation time of only 9.4 min (growth rate $\mu=4.43 \mathrm{~h}^{-1}$ ), which is less than half of that of E. coli and other important model organisms such as Bacillus subtilis even under optimal conditions (Eagon 1961; Hecker and Völker 1990; Sezonov et al. 2007; Hoffart et al. 2017).

While there exists a variety of synthetic biology tools for $V$. natriegens, including those for genetic and metabolic engineering, that allow for transformation efficiencies similar to E. coli, cultivation strategies to achieve very high-cell densities favorable to industrial processes have not been well reported in the literature so far (Weinstock et al. 2016; Dalia et al. 2017; Hoffart et al. 2017; Schleicher et al. 2018; Eichmann et al. 2019; Lee et al. 2019; Tschirhart et al. 2019). Fedbatch cultivations can be used to obtain high-celldensities by controlled supply of the carbon source. Due to a controlled growth rate at carbon limitation, undesired byproducts might be omitted and requirements like adequate levels of dissolved oxygen (DO) are met, which might be limited in large-scale processes.

In this study, we report the use of small scale deepwell sensor plates to screen for optimal $V$. natriegens growth conditions and parallelized fed-batch bioreactors to achieve high-cell-densities at laboratory benchtop-scales.

\section{Materials and methods}

Bacterial strain and chemical materials

Vibrio natriegens ATCC 14048 (wild type, DSM 759) from the German collection of microorganisms and cell cultures $\mathrm{GmbH}$ was used for all experiments. Chemicals were purchased from Sigma Aldrich (USA), Carl Roth GmbH \& Co. KG (Germany), Merck KGaA (Germany) or VWR Chemicals (USA).

Growth media and preculture conditions

$100 \mu \mathrm{L}$ of a $V$. natriegens cryostock stored at $-80{ }^{\circ} \mathrm{C}$ were used to inoculate a $125-\mathrm{mL}$ shake flask containing $10 \mathrm{~mL} \mathrm{LB}$ medium $\left(10 \mathrm{~g} \mathrm{~L}^{-1}\right.$ tryptone, $5 \mathrm{~g} \mathrm{~L}^{-1}$ yeast extract, $15 \mathrm{~g} \mathrm{~L}^{-1} \mathrm{NaCl}, \mathrm{pH} 7.5$ ), which was cultivated at $37{ }^{\circ} \mathrm{C}$ and $200 \mathrm{rpm}$ at $25 \mathrm{~mm}$ amplitude for 3-4 $\mathrm{h}$ and used to inoculate the main cultures while in the exponential growth phase at an optical density at $600 \mathrm{~nm}\left(\mathrm{OD}_{600}\right)$ of the preculture of about 1.5.

Development of small-scale culture conditions

Parallel cultivations in 24 deep-well-sensor plates (PreSens Precision Sensing GmbH, Regensburg, Germany) with different $\mathrm{NaCl}$ concentrations and buffer conditions were performed using the instant fed-batch medium EnPresso $\mathrm{B} \AA$ (Enpresso $\mathrm{GmbH}$, Berlin, Germany), which allows for an automatic, enzyme based, glucose limited fed-batch cultivation in smallscale. The 24 deep-well, flat bottom HydroDish ${ }^{\circledR}$ (HD24) and OxoDish ${ }^{\circledR}$ (OD24) plates are sterile, single use plates, equipped with pre-calibrated $\mathrm{pH}$ and DO sensors, respectively, to measure $\mathrm{pH}$ and DO online. The working volume was $1 \mathrm{~mL}$. The cultures were incubated at $37{ }^{\circ} \mathrm{C}$ in an orbital shaker $(25 \mathrm{~mm}$ amplitude, Infors HT, Bottmingen, Switzerland) for $24 \mathrm{~h}$ at $300 \mathrm{rpm}$. The tested conditions included six levels of $\mathrm{NaCl}$ concentrations, ranging from 0 to $24 \mathrm{~g}$ $\mathrm{L}^{-1}$ with the supplementation of $24 \mathrm{~g} \mathrm{~L}^{-1} 3-(N-$ morpholino)propane sulfonic acid (MOPS). Additionally, 0 and $12 \mathrm{~g} \mathrm{~L}^{-1} \mathrm{NaCl}$ were also tested without MOPS supplementation. Each $1 \mathrm{~mL}$ culture contained $0.1 \mu \mathrm{L}$ antifoam (PPG2000). The experiments were performed in triplicates on each plate, i.e. six aliquots of each cultivation condition.

Bioreactor fed-batch cultivations

Fed-batch cultivations were performed using mineral salt medium (MSM), which was sterilized in the bioreactors at $121{ }^{\circ} \mathrm{C}$ for $20 \mathrm{~min}$, consisting of $15 \mathrm{~g}$ $\mathrm{L}^{-1} \mathrm{NaCl}, 5 \mathrm{~g} \mathrm{~L}^{-1}\left(\mathrm{NH}_{4}\right)_{2} \mathrm{SO}_{4}, 1 \mathrm{~g} \mathrm{~L}^{-1} \mathrm{KH}_{2} \mathrm{PO}_{4}$ and $1 \mathrm{~g} \mathrm{~L}^{-1} \mathrm{~K}_{2} \mathrm{HPO}_{4}$. The medium was supplied with separately autoclaved glucose solution (20 min, 121 $\left.{ }^{\circ} \mathrm{C}\right)$ and sterile filtered $\mathrm{MgSO}_{4} \times 7 \mathrm{H}_{2} \mathrm{O}$ solution $(0.2$ $\mu \mathrm{M}$ CA filter) to obtain a final concentration of $10 \mathrm{~g}$ $\mathrm{L}^{-1}$ glucose and $0.5 \mathrm{~g} \mathrm{~L}^{1} \mathrm{MgSO}_{4} \times 7 \mathrm{H}_{2} \mathrm{O}$. To complete the medium $1 \%\left(\mathrm{v} \mathrm{v}^{-1}\right)$ of separately sterile filtered $100 \times$ trace element solution composed of: $1.64 \mathrm{~g} \mathrm{~L}^{-1} \mathrm{FeSO}_{4} \times 7 \mathrm{H}_{2} \mathrm{O}, 1.35 \mathrm{~g} \mathrm{~L}^{-1} \mathrm{CaCO}_{3} \times 2$ $\mathrm{H}_{2} \mathrm{O}, 1.0 \mathrm{~g} \mathrm{~L}^{-1} \mathrm{MnSO}_{4} \times \mathrm{H}_{2} \mathrm{O}, 0.1 \mathrm{~g} \mathrm{~L}^{-1} \mathrm{ZnSO}_{4} \times 7$ $\mathrm{H}_{2} \mathrm{O}, 0.03 \mathrm{~g} \mathrm{~L}^{-1} \mathrm{CuSO}_{4} \times 5 \mathrm{H}_{2} \mathrm{O}, 0.002 \mathrm{~g} \mathrm{~L}^{-1}$ $\mathrm{NiCl}_{2} \times 6 \mathrm{H}_{2} \mathrm{O}$ was added. The $\mathrm{pH}$ was adjusted to 7.50 by addition of $3 \mathrm{M} \mathrm{NaOH}$ or $1 \mathrm{M} \mathrm{H}_{3} \mathrm{PO}_{4}$. The feeding solution consisted of $600 \mathrm{~g} \mathrm{~L}^{-1}$ glucose, $15 \mathrm{~g}$ 
$\mathrm{L}^{-1} \mathrm{NaCl}, 20 \mathrm{~g} \mathrm{~L}^{-1}\left(\mathrm{NH}_{4}\right)_{2} \mathrm{SO}_{4}, 20 \mathrm{~g} \mathrm{~L}^{-1} \mathrm{KH}_{2} \mathrm{PO}_{4}$, $20 \mathrm{~g} \mathrm{~L}^{-1} \mathrm{~K}_{2} \mathrm{H}_{2} \mathrm{PO}_{4}, 5 \mathrm{~g} \mathrm{~L}^{-1} \mathrm{MgSO}_{4}$ and $1 \%\left(\mathrm{v} \mathrm{v}^{-1}\right)$ trace element solution, as well as $0.01 \%\left(\mathrm{v} \mathrm{v}^{-1}\right)$ PPG2000 as an antifoaming agent.

Fed-batch cultivations were performed in parallel benchtop stirred tank reactors with $1 \mathrm{~L}$ working volume (Multifors 2, Infors AG, Bottmingen, Switzerland). The temperature was set to 30 or $37{ }^{\circ} \mathrm{C}$, respectively. The $\mathrm{pH}$ value was maintained at 7.50 $\left( \pm 0.05\right.$ ) by addition of $3 \mathrm{M} \mathrm{NaOH}$ or $1 \mathrm{M} \mathrm{H}_{3} \mathrm{PO}_{4}$. The bioreactors were equipped with two six-blade Rushton impellers. The initial stirring speed and air flow were set to $200 \mathrm{rpm}$ and $0.5 \mathrm{vvm}$, respectively. In order to maintain the DO concentration above $40 \%$ during the cultivation an automated cascade consisting of an increased stirrer speed (200-1500 rpm), increased air flow $(0.5-2 \mathrm{vvm})$ and at last increased gas mix of oxygen in the supplied air $(0-70 \%)$, was used. Foam breakers made from cable ties were attached at the top of the stirrer shaft. Additionally, pulses of $0.1 \mathrm{~mL}$ of antifoam (PPG2000) where added manually whenever needed.

The fed-batch cultivations were started with an initial batch phase in $500 \mathrm{~mL}$ medium and the cultures were inoculated to an initial $\mathrm{OD}_{600}$ of 0.15 . After glucose depletion, the feed solution was fed exponentially according to Eq. 1 . The specific growth rate $\left(\mu_{\text {set }}\right)$ was set to $50 \%$ of $\mu_{\max }$.

$F(t)=F_{0} * e^{\mu_{s e t} * t}$.

The initial feed rate $F_{0}\left(\mathrm{~g} \mathrm{~h}^{-1}\right)$ was calculated using Eq. 2. The biomass concentration $(X)$ was estimated from a previously correlation of $\mathrm{OD}_{600}$ with cell dry weight (CDW) values. The biomass/substrate yield $Y_{\mathrm{X} / \mathrm{S}}$ was calculated from the batch phase with the initial glucose concentration $(S) . S_{\mathrm{i}}$ represents the glucose concentration of the feed solution and $X_{0}$ and $V_{0}$ are the biomass concentration and culture volume at the beginning of the fed-batch, respectively.

$F_{0}=\frac{\mu_{\text {set }}}{Y_{X / S} * S_{i}}\left(X_{0} V_{0}\right)$.

After $4 \mathrm{~h}$ of exponential feeding, the cultivation was continued for another $2 \mathrm{~h}$ with constant feeding at the last rate of the exponential feed.
Sampling and analytical methods during fed-batch cultivations

Samples of the culture broth were taken every hour to determine $\mathrm{OD}_{600}$ off-line in technical duplicates by using a standard UV cuvette spectrophotometer. Furthermore, $2 \mathrm{~mL}$ aliquots were filled into preweighed $2 \mathrm{~mL}$ reaction tubes for $\mathrm{CDW}$ determination in triplicates. The samples were centrifuged at $16,000 \times g$ at $4{ }^{\circ} \mathrm{C}$ for $10 \mathrm{~min}$ and the pellet was washed under the same conditions with $0.9 \% \mathrm{NaCl}$ before it was dried at $80{ }^{\circ} \mathrm{C}$. The supernatants were analyzed with the Cedex Bio HT Analyzer ${ }^{\circledR}$ (Roche Diagnostics International AG, Rotkreuz, Switzerland) using test kits for glucose, ammonia, acetate, ethanol, formate and lactate concentration (Glucose Bio HT, NH3 Bio HT, Acetate V2 Bio HT, Ethanol Bio HT, Formate Bio HT and Lactate Bio HT).

Exhaust gas data was recorded for one reactor for each temperature $\left(30\right.$ or $\left.37^{\circ} \mathrm{C}\right)$ during the fed-batch cultivation and served for the determination of the oxygen uptake rate $\left(O U R, Q_{\mathrm{O}_{2}}\right)$, carbon dioxide production rate $\left(Q_{\mathrm{CO}_{2}}\right)$, respiration coefficient $(R Q)$ and the volumetric oxygen transfer coefficient $\left(k_{L-}\right.$ a) via gas mass balance.

\section{Results}

Deep-well plate cultivations

To evaluate $V$. natriegens' response to different cultivation conditions $\mathrm{DO}$ and $\mathrm{pH}$ were monitored on-line. The cultures were grown in EnPresso B medium supplemented with different $\mathrm{NaCl}$ concentrations and with an optional addition of MOPS buffer (Fig. 1). During the first $2 \mathrm{~h}$ data indicates a short lag phase in all cultures. The $\mathrm{pH}$ decreased from an initial value of 7.5 rapidly to 7.0 within the first $4 \mathrm{~h}$, resembling typical growth behavior in batch cultivations due to ammonia uptake. In the following $2 \mathrm{~h}$ the $\mathrm{pH}$ remained stable with a subsequent rapid drop to 5.2-5.8 depending on the corresponding $\mathrm{OD}_{600}$ (Fig. 1). After $24 \mathrm{~h}$ no further growth was detected. The absence of $\mathrm{NaCl}$ results in slow growth and low $\mathrm{OD}_{600}$ values below 2 after $10 \mathrm{~h}$ of cultivation (Fig. 1a, c). $\mathrm{OD}_{600}$ after 1 day increased in the culture with additional MOPS buffer (Fig. 1c) while no buffer addition led to a decrease in the $\mathrm{OD}_{600}$ (Fig. 1a). 

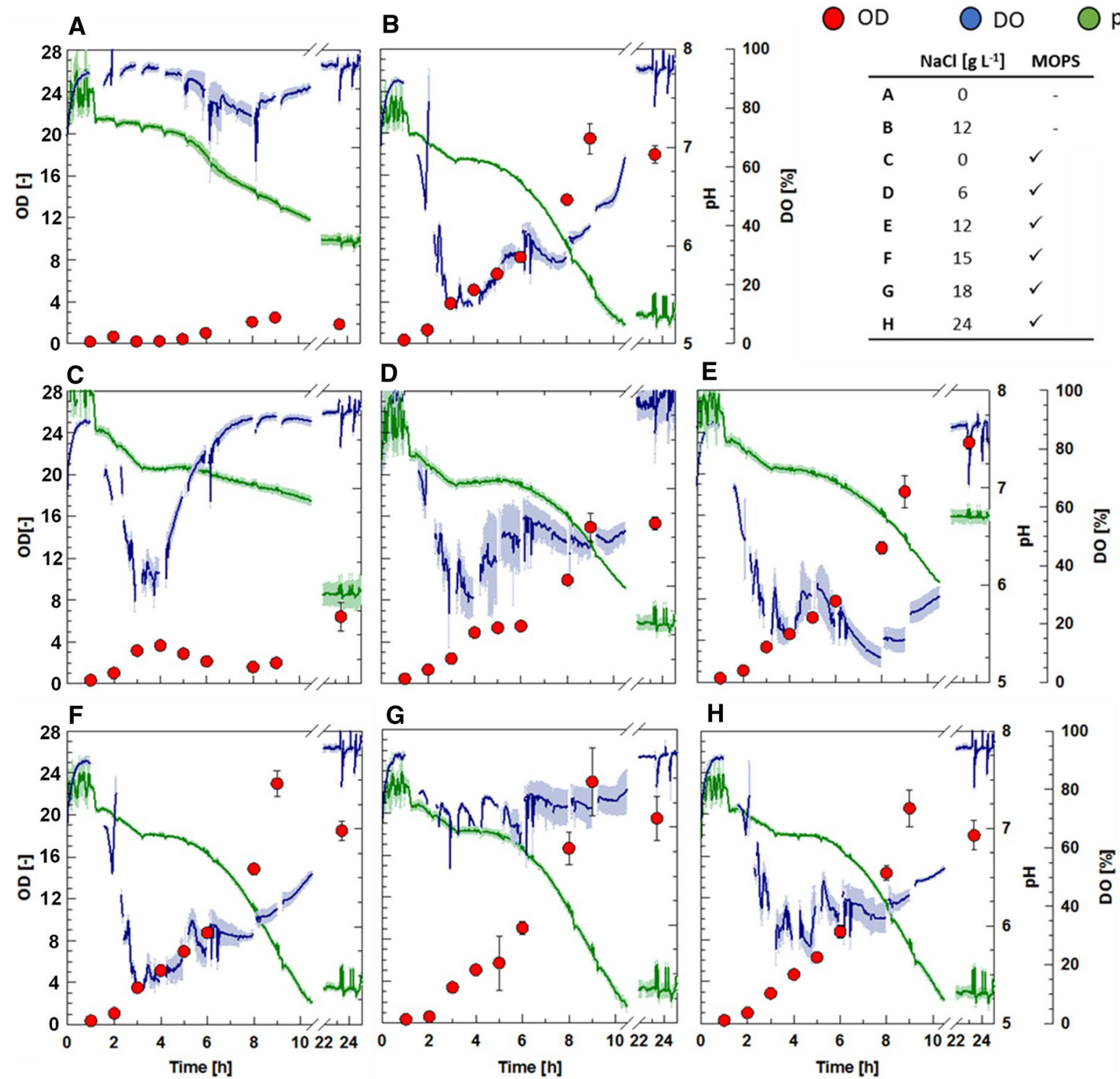

Fig. 1 Deep-well plate cultivations of Vibrio natriegens in EnPresso $\mathrm{B}{ }^{\circledR}$ medium supplemented with varying $\mathrm{NaCl}$ and 3-( $N$-morpholino)propane sulfonic acid (MOPS) amounts. The following amounts of $\mathrm{NaCl}$ were used $\left(\mathrm{g} \mathrm{L}^{-1}\right)$ : a $0, \mathbf{b} 12, \mathbf{c} 0, \mathbf{d} 6$, $\mathbf{e} 12, \mathbf{f} 15, \mathbf{g} 18$, and $\mathbf{h} 24$. $\mathbf{a}$ and $\mathbf{b}$ were not supplemented with MOPS, whereas $24 \mathrm{~g} \mathrm{~L}^{-1}$ MOPS were added to $\mathbf{c}-\mathbf{h}$. The

Between 4 and $6 \mathrm{~h}$ DO consumption is highest and correlates with fast cell growth. $\mathrm{NaCl}$ concentrations of about $12-18 \mathrm{~g} \mathrm{~L}^{-1}$ achieved higher $\mathrm{OD}_{600}$ of $20-24$ compared to lower $\mathrm{NaCl}$ concentrations after $10 \mathrm{~h}$ of cultivation (Fig. 1e-g). dissolved oxygen (DO) concentration and $\mathrm{pH}$ were monitored by using HydroDish ${ }^{\circledR}$ and OxoDish ${ }^{\circledR}$ plates, respectively. DO and $\mathrm{pH}$ data point are mean values from biological triplicates and $\mathrm{OD}_{600}$ data points represent mean values of six biological replicates. Error bars indicate $\pm \mathrm{SD}$

Fed-batch cultivations

To achieve high-cell-densities, glucose limited fedbatch cultivations were performed in 1-L stirred tank bioreactors at 37 and $30{ }^{\circ} \mathrm{C}$, respectively. The exponential slope of glucose consumption corresponds to the exponential growth behavior during 
the batch phase. Maximum specific growth rates $\left(\mu_{\max }\right)$ of $0.79 \mathrm{~h}^{-1}$ at $30{ }^{\circ} \mathrm{C}$ and $1.36 \mathrm{~h}^{-1}$ at $37{ }^{\circ} \mathrm{C}$ were determined during the batch phase. Glucose depletion was monitored to observe the end of the batch phase after $\sim 4 \mathrm{~h}$ of cultivation. Exponential feeding with $60 \%\left(\mathrm{w} \mathrm{v}^{-1}\right)$ glucose solution (feed medium) proceeded for another $4 \mathrm{~h}$ according to Eq. 1 . Afterwards a constant feed phase of $2 \mathrm{~h}$ followed. Biomass yield coefficient $\left(Y_{\mathrm{X} / \mathrm{S}}\right)$ after the batch phase was $0.36 \mathrm{~g} \mathrm{~g}^{-1}$ at $37^{\circ} \mathrm{C}$ and $0.71 \mathrm{~g} \mathrm{~g}^{-1}$ at $30^{\circ} \mathrm{C}$ with a $q_{\mathrm{s}}$ of 2.18 and $1.86 \mathrm{~g} \mathrm{~g}_{\mathrm{CDW}}{ }^{-1} \mathrm{~h}^{-1}$, respectively. During the controlled exponential feed, a growth rate of 0.58 $\mathrm{h}^{-1}$ at $30^{\circ} \mathrm{C}$ and of $0.42 \mathrm{~h}^{-1}$ at $37^{\circ} \mathrm{C}$ was obtained. In the constant feeding phase, the cultures at $30{ }^{\circ} \mathrm{C}$ accumulated a higher CDW of $55 \mathrm{~g} \mathrm{~L}^{-1}$ than the cultures at $37{ }^{\circ} \mathrm{C}$, which had decreased to $34 \mathrm{~g} \mathrm{~L}^{-1}$ until the end of the cultivation at $12 \mathrm{~h}$ (Fig. 2).

\section{Formation of side products}

The most abundant side product in the bioreactor cultivations was acetate, that accumulated during the batch phase while glucose was available in excess. Formation of acetate matched $q_{\mathrm{s}}$ at each temperature with differently fast growth rates. Acetate produced by $V$. natriegens during the batch phase was consumed again in the exponential fed-batch phase. In the subsequent constant feeding phase acetate accumulated again (Fig. 3). Although, no DO limitation occurred during the cultivations (Fig. 4), lactate and formate were produced at both cultivation temperatures. The lactate concentration decreased in the fedbatch phase at $30{ }^{\circ} \mathrm{C}$, whereas it increased during cultivations at $30{ }^{\circ} \mathrm{C}$. The formate formation stayed constant for both temperatures during the feeding phase (Fig. 4).

\section{Oxygen uptake rates}

The OUR during fed-batch cultivations remained mainly between 100 and 300, but maximum values of up to $500 \mathrm{mmol} \mathrm{L}^{-1} \mathrm{~h}^{-1}$ were reached during the exponential feeding phase (Figs. 4, 5). The high oxygen demand was met by acceleration of the stirrer speed, whenever a critical DO of $40 \%$ was reached. With increasing biomass, the gas flow was increased up to 2 vvm and supplied with up to $60 \%$ technical oxygen. This way, maximum $k_{L} a$ values of about 1600 $\mathrm{h}^{-1}$ and $1400 \mathrm{~h}^{-1}$ at 37 and $30{ }^{\circ} \mathrm{C}$ were obtained, respectively (Supplemental Fig. 1). In the batch phase, the specific oxygen uptake rate $\left(q_{\mathrm{O}_{2}}\right)$ was between 22 and $23 \mathrm{mmol} \mathrm{g} \mathrm{CDWw}^{-1} \mathrm{~h}^{-1}$ at $37^{\circ} \mathrm{C}$ and between 11 and $13 \mathrm{mmol} \mathrm{g}_{\mathrm{CDW}}{ }^{-1} \mathrm{~h}^{-1}$ at $30{ }^{\circ} \mathrm{C}$. Despite the different growth rates, $q_{\mathrm{O}_{2}}$ was comparable with 6-9 mmol $\mathrm{g}_{\mathrm{CDW}}{ }^{-1} \mathrm{~h}^{-1}$ at both temperatures during the exponential feeding phase (Table 1).

\section{Discussion}

High-cell-densities of $V$. natriegens by fed-batch cultivation using 1-L stirred tank bioreactors were shown for the first time. The aerobic cultivation included an initial batch phase, followed by a glucoselimiting exponential and a subsequent constant feeding phase. So far only batch, pulse based fed-batch or chemostat cultivations with cell density below $10 \mathrm{~g}$ $\mathrm{L}^{-1} \mathrm{CDW}$ have been described for $V$. natriegens (Rhodes and Payne 1962; Long et al. 2017; Schleicher et al. 2018; Becker et al. 2019; Erian et al. 2020). The observed maximum growth rate of $1.36 \mathrm{~h}^{-1}$ during the batch phase of the $37{ }^{\circ} \mathrm{C}$ bioreactor cultivations were comparable to the maximum growth rates in recent literature under similar conditions (Hoffart et al. 2017; Long et al. 2017). Specific oxygen uptake rates of $22 \mathrm{mmol} \mathrm{g} \mathrm{CDW}^{-1} \mathrm{~h}^{-1}$ of $V$. natriegens at $37^{\circ} \mathrm{C}$ during the batch phase were comparable to the results obtained by Long et al., who obtained a $q_{\mathrm{O}_{2}}$ of 28 mmol $\mathrm{g}_{\mathrm{CDW}}{ }^{-1} \mathrm{~h}^{-1}$ at $37{ }^{\circ} \mathrm{C}$ in minimal medium supplied with glucose and a growth rate of 1.7 (although complex media components were used) (Long et al. 2017). During the fed-batch cultivation high OURs of around 300, up to $500 \mathrm{mmol} \mathrm{L}^{-1} \mathrm{~h}^{-1}$ were observed. Such high oxygen demand is unfavorable for industrial scale cultivations due to limited power input. However, tailored aeration systems, e.g. nozzles, could be applied to achieve transfer efficiencies of almost $100 \%$ and oxygen transfer rates of 500 mmol L ${ }^{-31} \mathrm{~h}^{-1}$ (Noorman et al. 2018).

Towards the end of the fed-batch cultivation at $37{ }^{\circ} \mathrm{C}$ a CDW reduction from 39 to $34 \mathrm{~g} \mathrm{~L}^{-1}$ was observed, whereas the CDW could be increased up to 
$55 \mathrm{~g} \mathrm{~L}^{-1}$ during cultivations at $30{ }^{\circ} \mathrm{C}$ (Fig. 2). The decrease in biomass during the $37^{\circ} \mathrm{C}$ cultivations may arise from the spontaneous activation of prophages. Pfeifer et al. identified two inducible prophage regions on the first chromosome of V. natriegens ATCC 14048 (wild type, DSM 759), the same strain as used in this
Fig. 3 Production of acetate, lactate, and formate during the fed-batch cultivation of Vibrio natriegens at 30 and $37^{\circ} \mathrm{C}$. Data points are obtained from triplicate bioreactor cultivations. Error bars indicate \pm SD

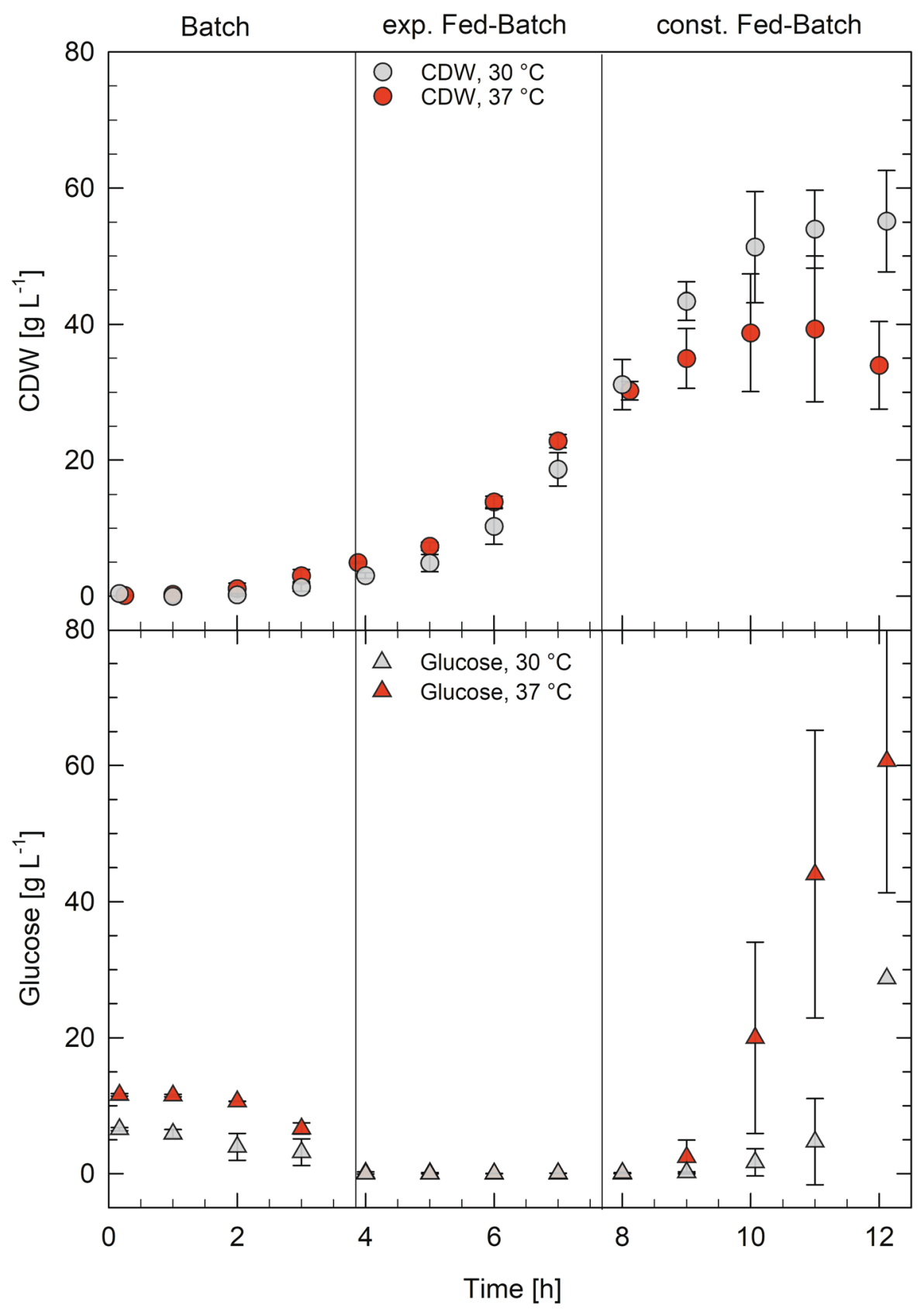

Fig. 2 Glucose limited fed-batch cultivations of Vibrio natriegens at $30^{\circ} \mathrm{C}$ (gray) and $37{ }^{\circ} \mathrm{C}$ (red). Cell dry weight (CDW) and glucose concentrations are shown. Data points are mean values of triplicate bioreactor cultivations. Error bars indicate \pm SD 


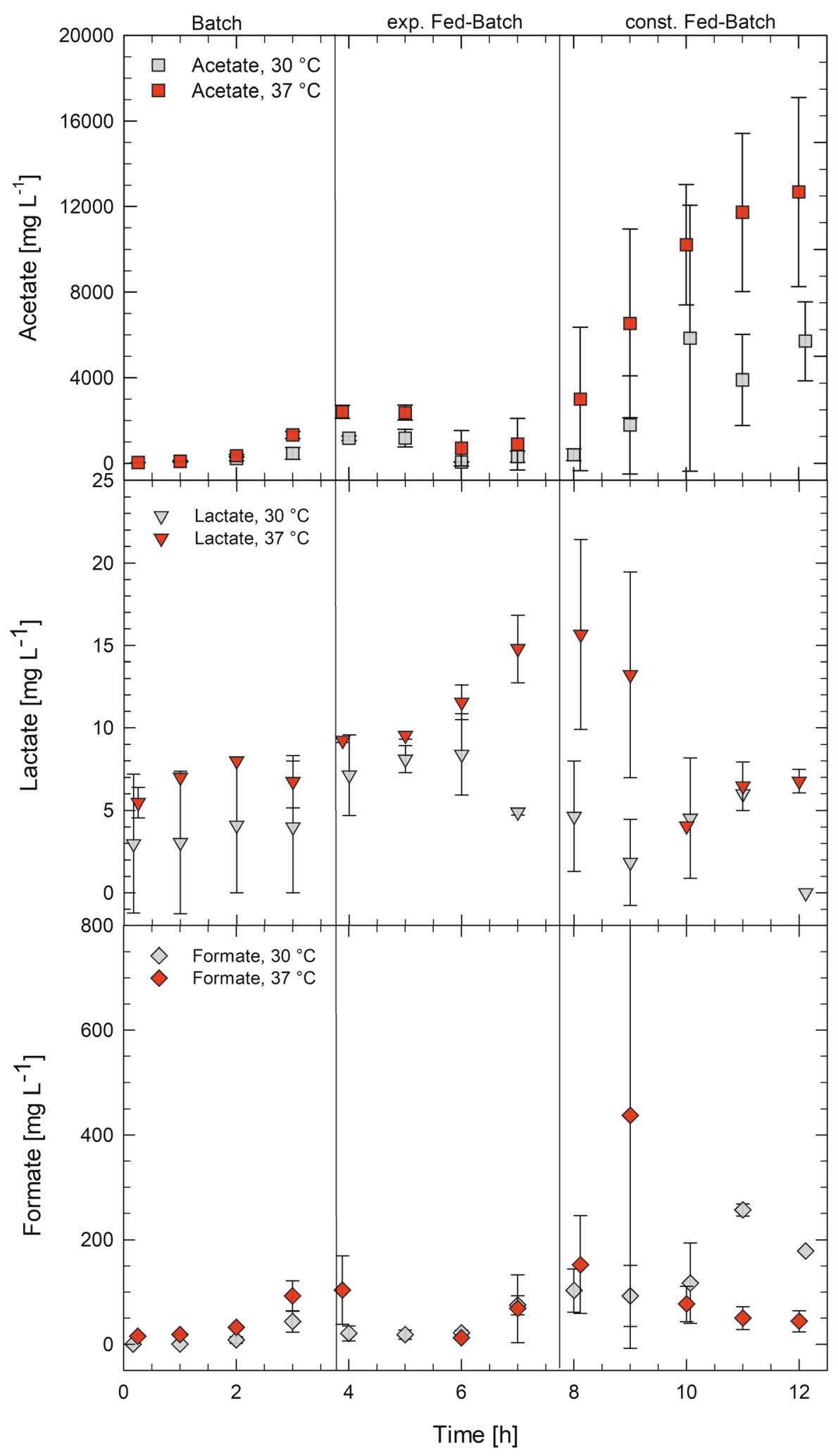




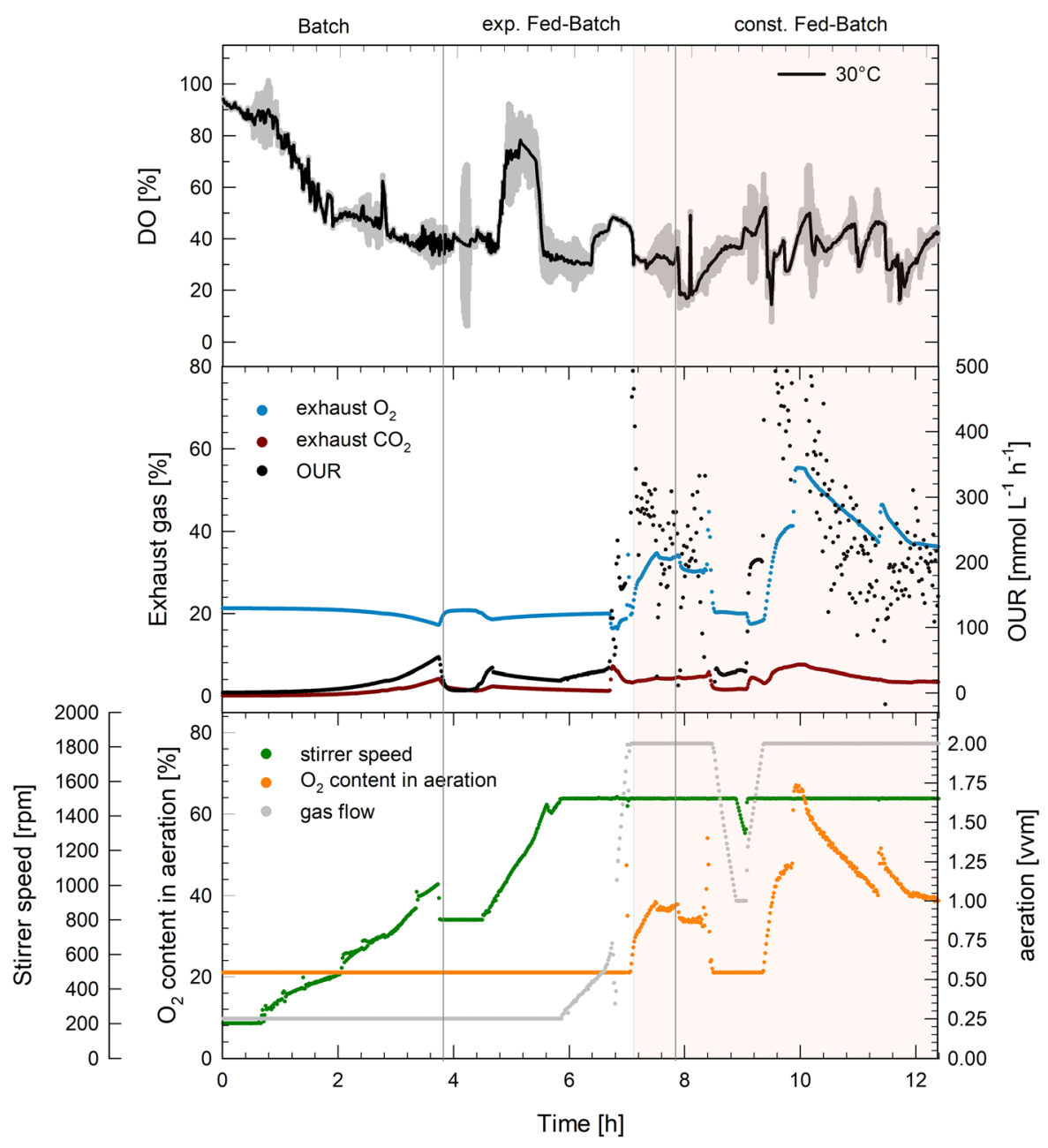

Fig. 4 Process data of Vibrio natriegens cultivations at $30{ }^{\circ} \mathrm{C}$. Average course of the dissolved oxygen concentration (DO) $(\%) \pm \mathrm{SD}$ (shaded area) during triplicate fed-batch cultivations (upper graph). Exhaust $\mathrm{O}_{2}$ and $\mathrm{CO}_{2}(\%)$ in the exhaust gas and oxygen uptake rate OUR $\left(\mathrm{mmol} \mathrm{L}^{-1} \mathrm{~h}^{-1}\right)$ of one reactor are

study (Pfeifer et al. 2019). Prophage induction was shown to happen spontaneously under standard cultivation conditions (Wiegand et al. 2018).

The instant medium EnPresso B (based on EnBase $^{\text {TM }}$ technology; Panula-Perälä et al. 2008), which enables a glucose limited fed-batch in mL-scale was used during deep-well plate cultivations. However, the growth behavior was not typical for EnPresso B cultivations, since no linear growth phase, through the enzyme controlled linear glucose release from starch, was visible after the batch phase (Fig. 1). Vibrio natriegens can utilize and hydrolyze a wide range of carbon sources (Hoffart et al. 2017; Ellis et al. shown in the middle graph, as well as the respective stirrer speed, oxygen content in the inlet air and aeration (lower graph). The orange shaded area represents the phase where technical oxygen was added to the supplied air

2019; Tschirhart et al. 2019). Therefore V. natriegens grew independent from the released glucose from the starch of the EnPresso B medium. However, no DO limitation occurred during these cultivations, indicating a slower growth on starch as on glucose. Consumption of the glucose excess in the EnPresso $B$ medium was visible through an increase of the DO concentration (Fig. 1).

To cope with the outstanding growth rates and fast metabolism of $V$. natriegens, suitable fermentation processes must be developed, to prevent the formation of overflow metabolites, which are reducing the biomass yield and become toxic with increasing 


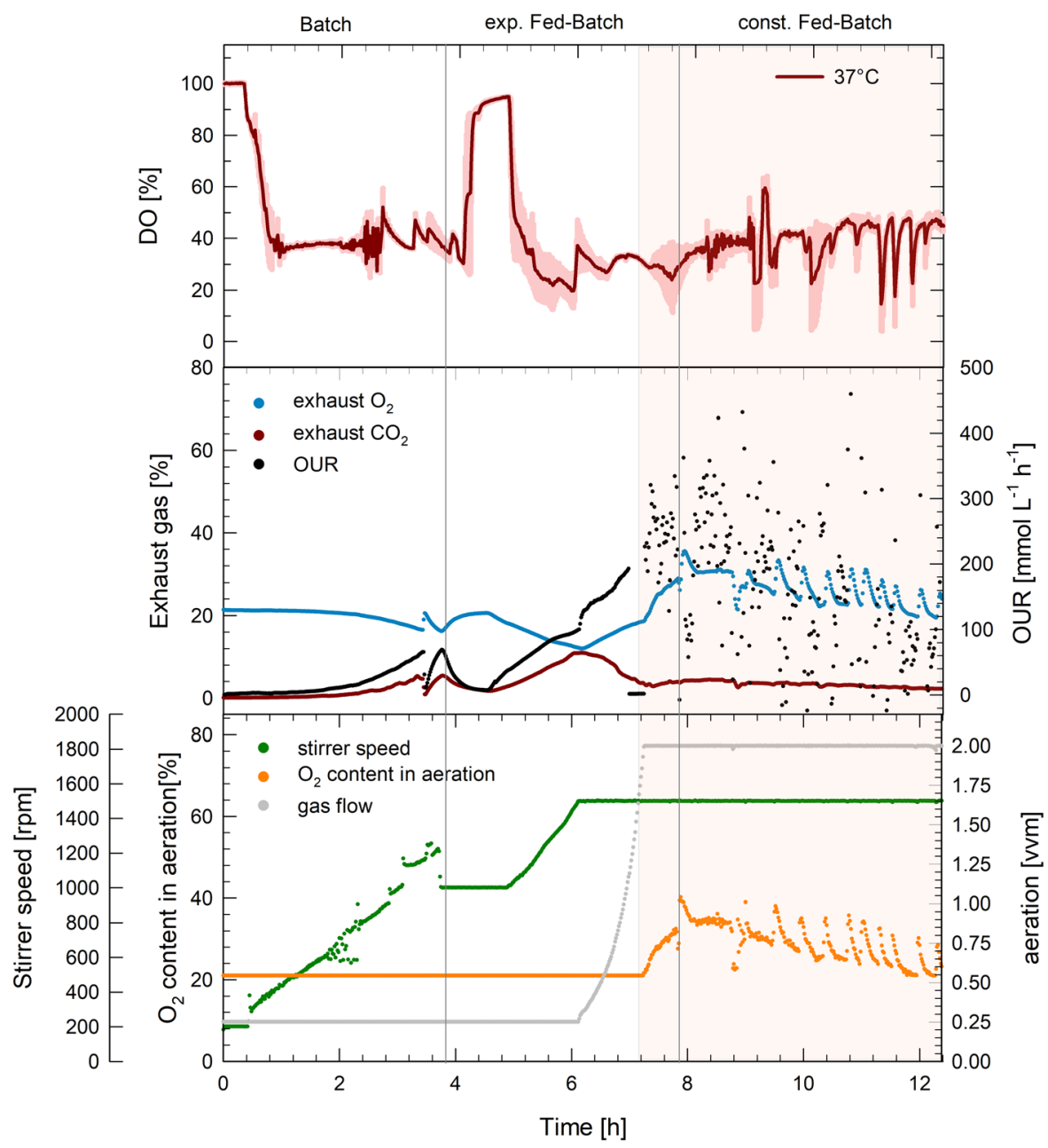

Fig. 5 Process data of Vibrio natriegens cultivations at $37^{\circ} \mathrm{C}$. Average course of the dissolved oxygen concentration (DO) $(\%) \pm \mathrm{SD}$ (shaded area) during triplicate fed-batch cultivations (upper graph). Exhaust $\mathrm{O}_{2}$ and $\mathrm{CO}_{2}(\%)$ in the exhaust gas and oxygen uptake rate OUR $\left(\mathrm{mmol} \mathrm{L}^{-1} \mathrm{~h}^{-1}\right)$ of one reactor are

shown in the middle graph, as well as the respective stirrer speed, oxygen content in the inlet air and aeration (lower graph). The orange shaded area represents the phase where technical oxygen was added to the supplied air

Table 1 Specific oxygen uptake rates during the batch and exponential fed-batch phase of the cultivations of Vibrio natriegens at 30 and $37{ }^{\circ} \mathrm{C}$

\begin{tabular}{lll}
\hline & $q_{\mathrm{O}_{2}, \text { batch }}\left(\mathrm{mmol} \mathrm{g}_{\mathrm{CDW}}{ }^{-1} \mathrm{~h}^{-1}\right)$ & $q_{\mathrm{O}_{2}, \text { exp. fed-batch }}\left(\mathrm{mmol} \mathrm{g}_{\mathrm{CDW}}{ }^{-1} \mathrm{~h}^{-1}\right)$ \\
\hline $30^{\circ} \mathrm{C}$ & $11-13$ & $7-9$ \\
$37^{\circ} \mathrm{C}$ & $22-23$ & $6-9$ \\
\hline
\end{tabular}

concentration (Neubauer et al. 2003). The production of mixed acid fermentation products was investigated in aerobic fed-batch cultivations at 30 and $37^{\circ} \mathrm{C}$. Interestingly, formate and lactate, beside acetate formation was obtained although no DO limitation occurred (Figs. 3, 4), while previously studies only observed acetate formation during aerobic batch cultivations (Hoffart et al. 2017; Long et al. 2017). Lowering the cultivation temperature from 37 to $30^{\circ} \mathrm{C}$ only led to a slightly lower formation of acetate, 
lactate and formate (Fig. 3). However, the total biomass could thereby be increased by $60 \%$, from 34 to $55 \mathrm{~g} \mathrm{~L}^{1}$, which resulted in a biomass productivity of $4.6 \mathrm{~g} \mathrm{~L}^{-1} \mathrm{~h}^{-1}$.

Pre-experiments in deep-well plates confirmed an ideal initial $\mathrm{NaCl}$ concentration of $15-18 \mathrm{~g} \mathrm{~L}^{-1}$ for aerobic $V$. natriegens cultivations (Fig. 1) (Hoffart et al. 2017; Long et al. 2017). The high $\mathrm{NaCl}$ demand of $V$. natriegens could be problematic in industrial applications due to $\mathrm{Cl}^{-}$speeding up corrosion of stainless steel bioreactors. However, the usage of high $\mathrm{NaCl}$ containing media can also allow for semi or even unsterile cultivation conditions, which reduces energy costs during industrial production processes (Yin et al. 2015). Also, with the trend going to different single use reactor systems, like orbital shaken bag reactors, corrosion might not even be a problem anymore (Oosterhuis et al. 2013).

\section{Conclusions}

High-cell-density fed-batch cultivations of $V$. natriegens were performed at deep-well- to bioreactor-scale and resulted in a maximum biomass productivity of $4.6 \mathrm{~g} \mathrm{~L}^{-1} \mathrm{~h}^{-1}$ with a total CDW of $55 \mathrm{~g} \mathrm{~L}^{-1}$ after $12 \mathrm{~h}$, in a glucose-limited fed-batch with $1.5 \% \mathrm{NaCl}$ at 30 ${ }^{\circ} \mathrm{C}$. The feeding strategy and a lower cultivation temperature led to less side products and higher biomass concentrations. The feasibility of a fed-batch cultivation of $V$. natriegens further highlights the organism's potential for industrial application and the future prospects to combine with the already available biotechnological tools to become an alternative production organism for e.g. recombinant protein production.

Acknowledgements We thank the Netzwerk Bioverfahrenstechnik Dresden e.V. from TU Dresden for hosting the $99 €$ bioreactor competition „Fast, faster, Vibrio natriegens", which gave us the motivation for this study. We thank Roche CustomBiotech (Mannheim, Germany) for the supply of the Cedex Bio HT Analyzer. We acknowledge support by the Open Access Publication Funds of TU Berlin.

Author contributions SLR and BG contributed to the conception and design of the study. BG, LA, MG, and IT carried out the experiments and analysis of the data. IT, BG, SLR prepared the first draft of the manuscript. All authors contributed to the manuscript revision and approved the submitted version.
Funding Open Access funding enabled and organized by Projekt DEAL. The authors received no specific funding for this work.

\section{Declarations}

Conflict of interest The authors declare that the research was conducted in the absence of any commercial or financial relationships that could be construed as a potential conflict of interest.

Ethical approval This article does not contain any studies with human participants or animals performed by any of the authors.

Open Access This article is licensed under a Creative Commons Attribution 4.0 International License, which permits use, sharing, adaptation, distribution and reproduction in any medium or format, as long as you give appropriate credit to the original author(s) and the source, provide a link to the Creative Commons licence, and indicate if changes were made. The images or other third party material in this article are included in the article's Creative Commons licence, unless indicated otherwise in a credit line to the material. If material is not included in the article's Creative Commons licence and your intended use is not permitted by statutory regulation or exceeds the permitted use, you will need to obtain permission directly from the copyright holder. To view a copy of this licence, visit http://creativecommons.org/licenses/by/4.0/.

\section{References}

Becker W, Wimberger F, Zangger K (2019) Vibrio natriegens: an alternative expression system for the high-yield production of isotopically labeled proteins. Biochemistry 58:2799-2803. https://doi.org/10.1021/acs.biochem. $9 \mathrm{~b} 00403$

Dalia TN, Hayes CA, Stolyar S et al (2017) Multiplex genome editing by natural transformation (MuGENT) for synthetic biology in Vibrio natriegens. ACS Synth Biol 6:1650-1655. https://doi.org/10.1021/acssynbio.7b00116

Eagon RG (1961) Pseudomonas natriegens, a marine bacterium with a generation time of less than 10 minutes. J Bacteriol 83:736-737

Eichmann J, Oberpaul M, Weidner T et al (2019) Selection of high producers from combinatorial libraries for the production of recombinant proteins in Escherichia coli and Vibrio natriegens. Front Bioeng Biotechnol 7:1-13. https:// doi.org/10.3389/fbioe.2019.00254

Ellis GA, Tschirhart T, Spangler J et al (2019) Exploiting the feedstock flexibility of the emergent synthetic biology chassis Vibrio natriegens for engineered natural product production. Mar Drugs 17:1-21. https://doi.org/10.3390/ md17120679

Erian AM, Freitag P, Gibisch M, Pflügl S (2020) High rate 2,3butanediol production with Vibrio natriegens. Bioresour 
Technol Rep 10:100408. https://doi.org/10.1016/j.biteb. 2020.100408

Hecker M, Völker U (1990) General stress proteins in Bacillus subitlis. FEMS Microbiol Ecol 74:197-214

Hoffart E, Grenz S, Lange J et al (2017) High substrate uptake rates empower Vibrio natriegens as production host for industrial biotechnology. Appl Environ Microbiol 83:1-10. https://doi.org/10.1128/AEM.01614-17

Lee HH, Ostrov N, Wong BG et al (2019) Functional genomics of the rapidly replicating bacterium Vibrio natriegens by CRISPRi. Nat Microbiol 4:1105-1113. https://doi.org/10. 1038/s41564-019-0423-8

Long CP, Gonzalez JE, Cipolla RM, Antoniewicz MR (2017) Metabolism of the fast-growing bacterium Vibrio natriegens elucidated by ${ }^{13} \mathrm{C}$ metabolic flux analysis. Metab Eng 44:191-197. https://doi.org/10.1016/j.ymben.2017.10.008

Neubauer P, Lin HY, Mathiszik B (2003) Metabolic load of recombinant protein production: inhibition of cellular capacities for glucose uptake and respiration after induction of a heterologous gene in Escherichia coli. Biotechnol Bioeng 83:53-64

Noorman HJ, van Winden W, Heijnen JJ, van der Lans RGJM (2018) Intensified fermentation processes and equipment. In: Górak A, Stankiewicz A, Siedl P (eds) Intensification of biobased processes. The Royal Society of Chemistry, Cambridge, pp 1-41

Oosterhuis NM, Neubauer P, Junne S (2013) Single-use bioreactors for microbial cultivation. Pharm Bioprocess 1:167-177. https://doi.org/10.4155/pbp.13.19

Panula-Perälä J, Šiurkus J, Vasala A et al (2008) Enzyme controlled glucose auto-delivery for high cell density cultivations in microplates and shake flasks. Microb Cell Factories 7:1-12. https://doi.org/10.1186/1475-2859-7-31

Pfeifer E, Michniewski S, Polen T et al (2019) Generation of a prophage-free variant of the fast-growing bacterium Vibrio natriegens. Appl Environ Microbiol 85:1-17. https://doi. org/10.1128/AEM.00853-19

Rhodes ME, Payne WJ (1962) Further observations on effects of cations on enzyme induction in marine bacteria. Antonie Van Leeuwenhoek 28:302-314. https://doi.org/10.1007/ BF02538743

Schleicher L, Muras V, Claussen B et al (2018) Vibrio natriegens as host for expression of multisubunit membrane protein complexes. Front Microbiol 9:1-10. https://doi. org/10.3389/fmicb.2018.02537

Sezonov G, Joseleau-Petit D, D’Ari R (2007) Escherichia coli physiology in Luria-Bertani broth. $\mathrm{J}$ Bacteriol 189:8746-8749. https://doi.org/10.1128/JB.01368-07

Tschirhart T, Shukla V, Kelly EE et al (2019) Synthetic biology tools for the fast-growing marine bacterium Vibrio natriegens. ACS Synth Biol 8:2069-2079. https://doi.org/ 10.1021/acssynbio.9b00176

Weinstock MT, Hesek ED, Wilson CM, Gibson DG (2016) Vibrio natriegens as a fast-growing host for molecular biology. Nat Methods 13:849-851. https://doi.org/10. 1038/nmeth.3970

Wiegand DJ, Lee HH, Ostrov N, Church GM (2018) Establishing a cell-free Vibrio natriegens expression system. ACS Synth Biol 7:2475-2479. https://doi.org/10.1021/ acssynbio.8b00222

Yin J, Chen JC, Wu Q, Chen GQ (2015) Halophiles, coming stars for industrial biotechnology. Biotechnol Adv 33:1433-1442. https://doi.org/10.1016/j.biotechadv.2014. 10.008

Publisher's Note Springer Nature remains neutral with regard to jurisdictional claims in published maps and institutional affiliations. 